\title{
CO-GENERATION AND MAINTENANCE OF 'DIALOGIC SPACE' BY MEANS OF VERBAL-GESTURAL INVOLVEMENT, WITH SOME PEDAGOGICAL IMPLICATIONS
}

\author{
JoAnNa Puppel, StanisŁaw PupPel
}

\begin{abstract}
We emphasize that 'dialogic space' is a precondition to the presence and maintenance of collective culture whose most conspicuous dimension is dialogic culture. We assume that dialogic culture constitutes the fullest dimension of humanity, and we highlight its role in a number of assumptions (1-8). Next, dialogic culture in terms of its properties is briefly discussed. We further assume that dialogic space in its verbal-non-verbal tanglements is of central significance in foreign language pedagogy and as such it should be present in foreign teaching/learning programs in order to help promote the positively-charged dialogue-oriented society of practice and at the same time exclude the proliferation of negatively-charged communications.
\end{abstract}

Key words: human condition, collective culture, dialogic culture, dialogic space, gestural involvement, intersubjectivity, Buber-Bakhtin Dialogic System (BBDS), hard boundaries, soft boundaries, dialogic pedagogy, maximally malignant monstrous language virus, community of practice

\section{Introduction}

It is next to impossible to imagine a full understanding of the 'human condition' in the communicative dimension without making recourse to the fact that humans are a strongly interactive/interacting species and conform both to what Hanna Arendt called vita activa and to 'being among men' (inter homines esse, see Arendt, 1958). Indeed, we may assume that humans permanently 'reside' in what may be referred to as a 'collective culture' of which 'dialogic culture' is the most conspicu- 
ous dimension, further propelled by human agent-human agent interactivity. Among the various dimensions of human interactivity, we interact with each other within what has been called 'dialogic space' (hence DS). Subsequently, the notion of 'dialogic space', which we assume to be an ingredient of 'dialogic culture', has justifiably entertained much attention in communicative performance studies. Moreover, as an extremely viable research notion it has gained a long history in the consideration of the problem of human communication and human communicative competence. One should recall, in this respect Socrates and the so-called 'socratic method of teaching' as, perhaps, the oldest known expression of the phenomenon of 'dialogicness', or application of the dialogical principle, ever attested in Western civilization (see e.g. Burnet, 1950; Sedley, 2003).

Needless to say, the notion of 'dialogic space' appears of utmost importance in focusing on and accounting for the interactive-communicative-expressive potential and practices of the human communicators (cf. seminal contributions, among others, by Buber, 1958; Bakhtin, 1981; Todorov, 1984; Holquist, 2002; Wegerif, 2011). In the present outline, the following general assumptions are put forth:

(1) It is assumed that 'dialogic space' constitutes an indispensable part of the Universal Communication Space (UCS, see Puppel, 2004) in which both language, meant as "a collective art of expression" (Sapir, 1921, Chapter XI: 5), together with the accompanying gestural involvement, form the constituents of the communicator's linguistic-communicative competence and which jointly produce the richness of human communicative practices.

(2) It is assumed that the co-creation and maintenance of dialogic space through additional gestural involvement, together with the primary (i.e. denotative) semanticization of the word, first of all 'gesturally semanticizes' (or gives meaning to) the natural 'gestural silence' surrounding every communicator (cf. Mehrabian, 1971), whereby this kind of semanticization further strengthens the verbal side of human communication. In this way, humans as communicative agents who are capable of generating collaborative coverbal complexes are also responsible for multi-modal communicative behaviour (cf. Bolt, 1987).

(3) It is assumed that dialogic space constitutes the particular communicator's 'operational space' (which may also be referred to as the 'practiced space') which is activated by the communicators by means of the linguistic resources functioning as the 'main operational system' (ie. the verbal system, MOS), strengthened by the 'supporting operational system' (i.e. the nonverbal system, SOS). In this way, the communicators maintain their daily relationships of mutuality and exchange (see e.g. de Certeau, 1984).

(4) In this vein, it is only natural to assume that the presence of dialogic space may also be regarded as being fundamental enough as to be additionally 'burdened' with being co-responsible for the generation of the phenomenon of human culture (cf. Tedlock and Mannheim, 1995). Simply, culture as such 
cannot be fully accounted for without making recourse to the presence of dialogic space.

(5) It is also assumed that otherwise natural gestural involvement in communicative acts makes the dialogic space more visible (see e.g. Merleau-Ponty, 1964) by additionally providing a gesturally mediated type of activity in the verbal acts of (interpersonal) communication.

(6) It is further assumed that gestural involvement whose presence constitutes the 'supporting operational system' considerably expands the word-centred dialogic space. This is accomplished by means of generating rich opportunities for the development and maintenance of various types of verbal-gestural communication, including mediational communication.

(7) It is assumed that the dimension of dialogic space, while involving the dominant position of the main operational system (the verbal code in human expression, i.e. in oral/written manifestations of language), and while being 'properly' (or simply 'necessarily' and unavoidably) supported by gestural involvements of all kinds, thus creates a specific 'speech - gesture' nonasymmetric 'mirror' system. The postulated system, whose non-asymmetricity results from the natural verbal dominance, operates most effectively in the dialogic space (cf. Gentilucci and Corballis, 2006).

(8) It is finally assumed that dialogic space provides an extremely desirable and extremely effective framework for the consideration of the ecolinguistic issue of natural language preservation, most clearly through the immersion of every natural language in dialogical ethnography in language use (cf. Bauman and Sherzer, 1989). Simply, the presence of dialogic space is a decisive factor in the preservation of language as the most important marker of humanity.

\section{Properties of dialogic space}

Dialogic space may be defined as the space in which people (i.e. the human communicators) can meet (or 'experience an encounter' with (an)other communicator(s)) in order to both communicate and directly experience their intersubjectivity. According to Buber (2002), dialogic space is the invisible space of the 'in-between', or the space lying between the two communicating parties, the 'I' and the 'Thou' which may also account for both the relevance of human grounding on Earth as well as for the relevance of various contextual determinants of human (interpersonal) doings.

Moreover, according to Bakhtin (1981), dialogic space is much more comprehensible than a simple mechanistic sender-receiver dyad and includes what he refers to as 'dialogism', where all linguistic understanding, or all the semiotic experience: 
(a) depends on 'otherness',

(b) acknowledges language as a 'shared event',

(c) relies on the relationship between 'self' and 'other', and

(d) where any possible text generated by the self-other dyad automatically constitutes the field of 'answerability'. In this way, answerability, being a part of communicative sharability, is also contained within a wider concept of 'responsiveness/interactivity' which characterizes communication in general.

It is this Buber-Bakhtin phenomenological understanding of dialogic space which we accept in the present outline as the most fundamental factor in human communication. Therefore, we propose to call this combination the 'Buber-Bakhtin dialogic system' (hence BBDS).

It should be emphasized at this point that the notions of self, other, I, thou, language as a shared event, and answerability most definitely and indisputably expand the classical production/perception 'Shannon-Weaver model of communication' (also called 'the mother of all models of communication', 1948; 1963) by making it highly intersubjective. The latter is accomplished by means of saturating it with undefinable and intangible interpersonal, therefore less mechanical and highly modifiable/changeable, properties. In this way, the classical notions of sender, encoder (transmitter), channel, decoder (receiver) and receiver (destination), originally applied to mechanical (tangible) devices, have received the 'human touch' and can thus be applied to all kinds of communicative exchanges occurring between/among human communicating agents involved in all kinds of communicative acts and practices.

It is especially the notion of 'answerability' which is at stake here, since dialogic space suggests a very special kind of human communicating agent-centred and message-centred sensitivity, that is, of the two communicating parties, the sender and the receiver, to each other, to the channel(s) in which messages are sent, to the messages transmitted, and to the fact that the two, the sender and the receiver, are 'sunk', as it were, in a very special kind of space, that is, the intersubjective I-Thou space which binds the two communicating parties. The nature of the latter is such that it allows for bilateral and practically limitless sender-receiver exchanges of messages (the socalled interchangeability of roles) as well as a simultaneous exertion of mutual control of all the accompanying 'soft' phenomena (such as intentions, emotions, use of linguistic/non-linguistic resources whose quality and volume are dictated by the proclivities of the context, etc.).

Moreover, in the present account, it should be borne in mind that the notion of 'dialogic space' most necessarily involves the more fundamental constituent notion of 'space' which has been defined in the history of science and philosophy as either an entity, a relationship holding between/among entities/agents (or the kind of social space, see. e.g. Puppel and Puppel, 2010), or as a part of a general conceptual framework of human understanding of the world/universe (see, e.g. Carnap, 1995). 
Throughout the rich volume of human attempts to definitively resolve the problem, the matter has not, however, been given any final solution and, therefore, we feel fully excused to accept the three as legitimately and jointly bearing on our understanding of the said notion. One should also bear in mind that space has an inseparable 'partner' of time (the temporal dimension). The latter has always been treated as a 'fourth dimension' in relation to space (see e.g. Tenbrink, 2007). It is, therefore, this spatial-temporal alignment that must be treated as the physical underpinning of the linguistic-communicative practices within the central notion of 'dialogic space'.

As a consequence, in the present outline, all of the properties enumerated above are assumed to constitute the boundaries of 'dialogic space' which is meant here as both an entity (with every entity additionally understood as a temporal-spatial design), an inter-entity (inter-agent) relationship and at the same time a part of the human understanding of the universe and our place in it.

More precisely, the boundaries of dialogic space appear to be of two kinds: (a) the 'hard' physical (i.e. embodied) boundaries (HB) of the very bodies of the communicators functioning in their traditional roles of sender $(\mathrm{S})$ and receiver $(\mathrm{R})$, and (b) the 'soft' boundaries (determinants, SB), such as: the channels (C) to be used in message exchanges (i.e. audio-vocal: oral, visual-tactile: written/printed, signed, hybrid: audio-vocal/visual-tactile), the messages themselves (M), the communicator's intentions (I), the emotions involved (E), and the whole bulk of linguistic/nonlinguistic resources (LR), that is, both the MOS and SOS, activated in contextsensitive communicative acts.

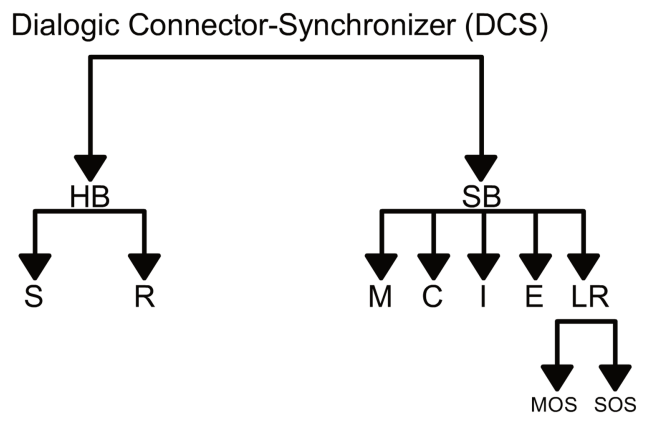

Fig. 1. The architecture of the dialogic connector-synchronizer (DCS) which operates within the BBDS

Where:
$\mathrm{S}$ - Sender of messages (individual or collec- C - channel tive, also intersubjective ' $I$ ') I $\quad$ intentions
$\mathrm{R}$ - Receiver of messages (individual or collec- E - emotions tive, also intersubjective 'Thou') LR - linguistic and non-linguistic resources
HB - hard boundaries
SB - soft boundaries
DId - dialogic identity of a communicator
M - message
MOS - main operating system (language as a code)
SOS - supplementary operating system (non-verbal supplement to language) 
The relationship between the two types of boundaries, the hard boundaries and the soft boundaries, may be represented by means of a generic device which we propose to call the 'dialogic connector-synchronizer' (DCS). It forms a system of coordinates which further represent a network of complex interrelations. The latter converge in the 'dialogic identity of every communicator' (DId) as an outcome of these interrelations generated in every communicative act. The postulated dialogic connector-synchronizer may be represented by means of the following diagram (Fig. 1).

The above analysis has led us to propose that the properties of dialogic space (DS) may include the following:

- DS is relational: it allows for and prompts the formation of inter-communicator connections (linkages),

- DS is productive: it allows for the use of the combined verbal/non-verbal resources in an endless variety of communicative tasks tailored to the proclivities of the ever changing context,

- DS is heterogenous: it allows for the making of maximally diversified communicative behaviours,

- DS is punctuated: it allows for the use of discrete and linear types of ver$\mathrm{bal} /$ nonverbal complexes,

- DS is desired: it provides the environment which is compelling and unavoidable in the sense that it is the dialogic environment in which all the communicators meet, which they cannot avoid and which somehow 'forces' them to perform verbally-gesturally in the BBDS. In this way, they all conform to responsiveness inherent in the BBDS and participate in the human 'desire for language' (see logoepithymia, Puppel, 2018),

- DS is differentiated: it is not uniform with respect to the relations holding between I and Thou and, generally, message quality. In this regard and on the basis of observations and communicator intuitions, one is compelled to assume that the following basic I-Thou relations can be envisaged: (a) the I-centred DS (I-dominant): where the 'I' dominates, and in extreme cases, linguistic expressions, especially when the sender's anonymity (as opposed to formal 'authorship') is involved and guaranteed (as is the case with some most recent electronic communications and internet trolling and bullying), demonstrate a negative side, such as the cyber-communicators' rather degenerative (and infectious) tendency towards an excessive use of negatively-loaded parameters of rejection, negation, contempt and derision demonstrated towards the 'Thou', additionally accompanied by the communicator's concomitant use of the lowest possible language resources. In fact, one may even talk of language being used like an infectious 'language virus'. In this case we propose to identify language as MMMLV (that is, 'maximally malignant monstrous language virus'), or a RENEGADE communicative phenomenon which involves such behavioural markers as: REjection, NEGation, and DErision. 
This type of relations is easiest to attain by the communicators. The other type of relation is (b) the Thou-centred DS (Thou-dominant): where 'Thou' dominates and where all of the communications are governed by the dominating presence of 'Thou'. Needless to say, this kind of relation and interaction is socially most desired and also most empathetic but, at the same time, very difficult to attain because of its marked status. Finally, (c) the balanced I-Thou DS (I-Thou balanced) where both 'I' and 'Thou' remain in a balanced type of relationship. It should be observed that the latter type of relation is most difficult to attain and requires the highest degree of communicator awareness (cf. e.g. Brignall and Van Valey, 2005). The three types of relations may be graphically represented as follows (Fig. 2):

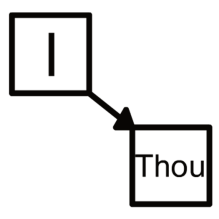

(a) I-dominant

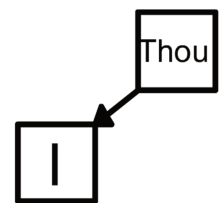

(b) Thou-dominant

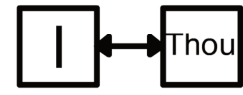

(c) I-Thou balanced

Fig. 2. The three types of 'I - Thou' relations which generate highly differentiated communicative outcomes (see text above)

Furthermore, the above remarks allow one to organize dialogic space (DS) into the following matrix of properties:

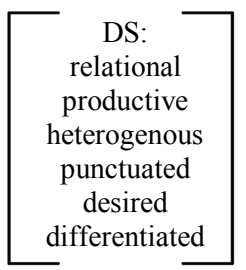

Fig. 3. The DS Matrix

\section{Some pedagogical implications of dialogic space}

It is proposed here that dialogic space contributes nontrivially to the formation of the overall ecology of human communication and does have substantial relevance not only for human communicative competence and human communication in general, but also, in a narrower perspective, matters significantly for pedagogical practice, including foreign language teaching/learning practice. The idea of immersing foreign 
language teaching/learning practices generally in dialogic culture, dialogic pedagogy (cf. Matusov, 2009), and more specifically in dialogic space, is not new and has, in fact, always been present in foreign language pedagogy studies, for example, under the guise of 'the social context of learning' (see e.g. Vygotsky, 1978; Breen, 1985; Tharp and Gallimore, 1988; Tiberius and Billson, 1991). In the present outline, however, it is made more explicable within the BBDS framework outlined above.

The BBDS framework proposed here focuses very strongly not so much on the $\mathrm{HB}$, as it does on the SB of the system, especially on the central ideas of answerability (responsiveness) and sharability, that is, on sharing words (or, more generally, the verbal aspects of communication) between the 'I' and the 'Thou', however, with a very strong support of the socially sharable gestural involvement (cf. Flecha, 2000; J. Puppel, 2015). In this way, one may imagine that dialogic space assumes the shape of a multi-modal (i.e. verbal-gestural) 'community of practice', where the verbal aspect of communication cannot be separated from the gestural one in the operational space/practiced space and where the MOS-SOS verbal-gestural complex is not only present but where its presence is additionally very strongly goal-oriented (cf. Wenger, 1998, for a discussion of the concept of 'community of practice'; also Plaza, 2010).

Its strong goal-oriented nature is connected with the general task of providing efficient foreign language teaching and learning framework and with viewing the teacher-learner dyad as forming a highly motivated, and therefore integrated/interactive, community of egalitarian communicative practice involved in the 'dialogic generation of knowledge' as well as in the transformation of the classroom into a dialogic (i.e. responsive/interactive) community (see e.g. Wenden, 1983; Tharp et al., 2000). The latter term implies that it involves such joint activities (or discourse-oriented shared practice, cf. Cary, 2006) as: discussions, giving each other mutual verbal assistance, necessarily sharing repertoires of resources (e.g. cognitive, cultural, linguistic, non-linguistic) as well as necessarily respecting 'the I-Thou' identities through these mutualities.

It is in this general setup that dialogic space in the senses discussed above appears to be of utmost pedagogical relevance. More precisely, it is there where the establishment of integrated verbal-gestural communicative competence of a communicator, especially a foreign language communicator, can be secured in the best possible way in order to serve the communicators in their highly intersubjective, context-sensitive, effective, successful and mutually respectful communicative practice.

\section{Concluding remarks}

In this essay, we have emphasized that 'dialogic space' is a necessary precondition to the generation, presence and maintenance of collective culture whose most conspicuous dimension is dialogic culture. Since the very presence of dialogic cul- 
ture is assumed to constitute the fullest dimension of humanity, its role has been highlighted in a number of assumptions (1-8) as well as its properties have been briefly discussed. No doubt, it appears that dialogic space in its rich verbal-nonverbal 'tanglements', as shown in the DCS, is of central significance in foreign language pedagogy and as such it should be mandatorily articulated in foreign teaching/learning programs.

This should be done in order to help promote the positively-charged dialogueoriented society of practice and at the same time exclude, or at least minimize, the proliferation of negatively-charged communications which, as of late, seem to be on the rise due to the communicators' massive access to most advanced technological devices whose presence favours the proliferation of anonymous and strongly I-dominant daily communications. In consequence, the rising presence of negatively-charged communications threatens the very existence of DS and of the society of practice based on empathy, mutual understanding and the need to cooperate for common good.

\section{References}

Arendt, H. 1958/2013. The human condition. Chicago: The University of Chicago Press.

Bakhtin, M. 1981. The dialogic imagination. Four essays by M.M. Bakhtin. Austin, TX: University of Texas Press.

Bauman, R. and J. Sherzer. (eds.). 1989. Explorations in the ethnography of speaking. Cambridge: Cambridge University Press.

Bolt, R.A. 1987. „The integrated multi-modal interface”. Transactions of the Institute of Electronics, Information and Communication Engineers (Japan), J79-D(11). 2017-2025.

Breen, M.P. 1985. „The social context for language learning - a neglected situation?”. Studies in Second Language Acquisition 7.2. 135-158.

Brignall, T.W. and T. Van Valey. 2005. „The impact of internet communications on social interaction”. Sociological Spectrum 25.3. 335-348.

Buber, M. 1958. I and thou. 2nd ed. Edinburgh: T. and T. Clark.

Burnet, J. 1920/1950. Greek philosophy: from Thales to Plato. London: Macmillan.

Carnap, R. 1995. An introduction to the philosophy of science. New York: Dover Publications.

Cary, L.J. 2006. Curriculum spaces: discourse, postmodern theory and educational research. Frankfurt am Main: Peter Lang.

de Certeau, M. 1984. The practice of everyday life. Berkeley, CA: University of California Press.

Flecha, R. 2000. Sharing words: theory and practice of dialogic learning. Oxford: Rowman and Littlefield.

Gentilucci, M. and M.C. Corbalis. 2006. „From manual gesture to speech: a graduał transition”. Neuroscience and Biobehavioral Reviews 30. 949-960.

Holquist, M. 2002. Dialogism: Bakhtin and his world. London: Routledge.

Jesson, R. 2016. „Creating dialogic spaces: talk as a mediational tool in becoming a writer”. International Journal of Education Research 80. 155-163.

Matusov, E. 2009. Journey into dialogic pedagogy. New York: Nova Science Publishers.

Mehrabian, A. 1972. Silent messages: implicit communication of emotions and attitudes. Belmont, CA: Wadsworth Publishing Company. 
Merleau-Ponty, M. 1964. Le visible et L'invisible. Paris: Gallimard.

Plaza, S.R. 2010. „Egalitarian dialogue and instrumental dimension. Two principles of dialogic learning in the classroom". Psychology, Society and Education 2.1. 61-70.

Puppel, J. 2015. „Siła performatywna komunikacji niewerbalnej używana przez nauczyciela i ucznia w formalnych warunkach klasy". In Puppel, S. (ed.). MOTEK. Motywy ekolingwistyczne: $w$ strone ekoglottodydaktyki. Poznań: Zakład Graficzny UAM. 133-141.

Puppel, S. 2004. „An outline of a domain-resource-agent-access-management (DRAAM) model of human communication: towards an ecology of human communication". Working Papers of the Department of Ecocommunication Oikeios Logos $\mathrm{Nr}$ 1. 1-26.

Puppel, S. 2018. „On the workings of the 'language kite': towards a holistic account of the human linguistic-communicative endeavour (de laboribus milvi linguae)". In Bielak, M., S. Puppel and W. Maliszewski. (eds). Linguolabourese: language and communication in action. Advances in elinguistics. 57-66.

Puppel, S. and J. Puppel. 2010. "Some notes on the role of the hand-arm system (HAS) in the ecology of human communication". Working Papers of the Department of Ecocommunication Oikeios Logos Nr 6. 1-9.

Sapir, E. 1921. Language: an introduction to the study of speech. New York; Harcourt, Brace.

Shannon, C.E. 1948. „A mathematical theory of communication”. Bell System Technical Journal 27. 379-423, 623-656.

Sedley, D. 2003. The Cambridge companion to Greek and Roman philosophy. Cambridge: Cambridge University Press.

Shannon, C.E. and W. Weaver. 1963. The mathematical theory of communication. Urbana, IL: University of Illinois Press.

Tedlock, D. and B. Mannheim. (eds.) 1995. The dialogic emergence of culture. Urbana and Chicago: University of Illinois Press.

Tenbrink, T. 2007. Space, time, and the use of language: an investigation of relationships. Berlin: Mouton de Gruyter.

Tharp. R.G. and R. Gallimore. 1988. Rousing minds to life: teaching, learning, and schooling in social context. Cambridge: Cambridge University Press.

Tharp, R.G., P. Estrada, S.S. Dalton and L.A. Yamauchi. 2000. Teaching transformed: achieving excellence, fairness, inclusion, and harmony. Boulder, CO: Westview Press.

Tiberius, R.G. and J.M. Billson. 1991. „The social context of teaching and learning”. New Directions for Teaching and Learning 45. 67-86.

Todorov, T. 1984. Mikhail Bakhtin: the dialogical principle. Minneapolis: The University of Minnesota Press.

Vygotsky, L.S. 1978. Mind in society: the development of higher psychological processes. Cambridge, Mass.: Harvard University Press.

Wegerif, R. 2011. „Towards a dialogic theory of how children learn to think”. Thinking Skills and Creativity 6. 179-190.

Wenden, A.L. 1983. „The process of interaction”. Language Learning 33. 103-121.

Wenger, E. 1998. Communities of practice: learning, meaning, and identity. Cambridge: Cambridge University Press. 